\title{
Circadian rhythms of locomotor activity in the reddish-grey musk shrew (Eulipotyphla: Soricidae) from South Africa
}

\author{
I. van der Merwe ${ }^{1}$, M. K. Oosthuizen ${ }^{2}$, C. T. Chimimba ${ }^{3}$ \& N. C. Bennett ${ }^{1,2,4}$ \\ 1 Department of Zoology and Entomology, University of Pretoria, Pretoria, South Africa \\ 2 Department of Zoology and Entomology, Mammal Research Institute (MRI), University of Pretoria, Pretoria, South Africa \\ 3 Department of Zoology \& Entomology, DST-NRF Centre of Excellence for Invasion Biology (CIB), University of Pretoria, Pretoria, South Africa \\ 4 Department of Zoology, King Saud University, Riyadh, Saudi Arabia
}

\begin{abstract}
Keywords
locomotor activity; Circadian rhythm;

Soricidae; free-run; Crocidura cyanea.

\author{
Correspondence \\ Maria K. Oosthuizen, Department of \\ Zoology and Entomology, Mammal \\ Research Institute (MRI), University of \\ Pretoria, Pretoria 0002, South Africa. \\ Email: moosthuizen@zoology.up.ac.za
}

\begin{abstract}
The circadian rhythm of locomotor activity in a southern African shrew, the reddish-grey musk shrew Crocidura cyanea was investigated. Thirteen individuals were subjected to three successive light cycles, each cycle lasting approximately 2 weeks: an LD cycle (12 h light/12 h dark), a DD cycle (constant darkness) and a DL cycle (an inverse of the LD cycle). All of the animals exhibited entrainment of their activity to the LD and DL lighting regimes. Locomotor activity of $C$. cyanea occurred predominantly during the dark phases of the LD cycle and the DL cycle. Under LD, the mean active phase (a) of C. cyanea was $10.8 \pm 0.3 \mathrm{~h}$ and the total percentage of activity was $78.9 \%$ during the dark phase. When subjected to constant darkness, the mean active phase increased to $13.2 \pm 01.8 \mathrm{~h}$ and all animals expressed free-running rhythms of locomotor activity (mean $\pm 1 \mathrm{SD}=23.0 \pm 0.55 \mathrm{~h}$; range $=22.4-23.7 \mathrm{~h}$ ). On the reverse LD cycle, the mean active phase was lowest $(09.3 \pm 0.16 \mathrm{~h})$ and the total percentage of activity was $71.5 \%$ during the dark phase of the cycle. The reddish-grey musk shrew possesses a strong circadian rhythm of locomotor activity that predominantly occurs during the dark phase and consequently the musk shrew may essentially be considered a nocturnal mammal.
\end{abstract}

\section{Introduction}

Many living organisms possess biological rhythms that may vary in duration from a few milliseconds through to more than a year. To maintain synchrony between multiple physiological or behavioural rhythms and the external geophysical cycle, biological rhythms entrain to an external zeitgeber. The most prominent time cue utilized by mammals is the environmental light-dark cycle (Kumar, 1997; Goldman, 1999; Benstaali et al., 2001). In the absence of an external zeitgeber or time giver, biological rhythms express their innate rhythmicity (Aschoff, 1960) and are termed circadian if they have a length of c. 24 h (Haus et al., 1998). A free-running endogenous rhythm is indicative of a functional biological clock which is responsible for controlling the circadian rhythm (Stephan \& Zucker, 1972; Mosko \& Moore, 1978; Aschoff, 1981). Furthermore, the free-running period, or Tau $(t)$, reflects inter-individual variation within a species and generally ranges between 22 and $26 \mathrm{~h}$ under constant darkness (Aschoff, 1981).

In most mammals, the light-dark cycle entrains locomotor activity to a certain phase or phases of each day (day/ night/twilight), which is generally used to categorize species as being nocturnal, diurnal or crepuscular. These phases are representative of certain environmental conditions and differ in their levels of illumination, whereby light generally induces locomotor activity in diurnal animals but suppresses locomotor activity in nocturnal animals (Daan \& Aschoff, 1981). Therefore, entrainment of locomotor activity to the light-dark cycle is able to prepare individuals for predictable environmental changes in temperature, food and prey availability, mates and predation risk (Kronfeld-Schor \& Dayan, 2008). Endogenously entrained activity rhythms also provide benefits to ecological communities. Many small mammal communities are able to support multiple sympatric species when resource competition is reduced and this may be achieved by species being active at alternative times of the day or night (Shkolnik 1971; Vieira \& Baumgarten, 1995; Rychlik, 2005; Sidorovich, Polozov \& Solovej, 2008).

Locomotor activity is a complex behaviour, the mobile response of an animal to several biotic and abiotic factors, for example the presence or absence of competitors or predators, population structure, temperature or food availability (Vieira \& Baumgarten, 1995; Kelt et al., 2004; Brandt \& McCay, 2005; Kronfeld-Schor \& Dayan, 2008). Many non-photic factors (e.g. temperature, food, air pressure) may also become entraining agents of activity (Aschoff, 1981). The control of the circadian locomotor activity rhythm is thus flexible and furthermore adaptive to both short-term as well as long-term environmental changes. For example, some mammals such as 
the European rabbit Orictolagus cuniculus, the yellow-bellied marmot Marmota flaviventris and the northern short-tailed shrew Blarina brevicauda, display short-term responses to the weather by increasing their level of activity on cloudy days (Getz, 1961; Travis \& Armitage, 1972; Villafuerte et al., 1993). In contrast, other animals adjust or even shift their locomotor activity to a different phase of the day or on a seasonal basis as a means to avoid for example thermoregulatory and energetic costs. Although many of these non-photic stimuli may directly affect the survival of animals, the light-dark cycle remains the most predictable time cue, which is largely indicative of favourable environmental conditions (Kronfeld-Schor \& Dayan, 2008). Furthermore, nocturnal and diurnal animals usually differ in their physiological characteristics and may not only be adapted to but also in some cases be constrained to either night or day (Roll, Dayan \& Kronfeld-Schor, 2006; Kronfeld-Schor \& Dayan, 2008).

Shrews are small mammals with characteristically high energetic demands whose diet comprises primarily of insects and other invertebrate prey (Nagy, Girard \& Brown, 1999; Skinner \& Chimimba, 2005). Shrews form the family Soricidae and are one of the most speciose families of mammal comprising more than 300 known species (Wojcik \& Wolsan, 1998), and needless to say, a large number of species remain unstudied. Of the studies conducted on soricid shrews, most have focused on the more common and easily collected species such as the Asian house shrew Suncus murinus, the northern short-tailed shrew and the common shrew Sorex araneus, none of which are endemic to Africa. Two sub-families, the white-toothed shrews (Crocidurinae) and the African white-toothed shrews (Myosoricinae), occur in Africa (Skinner \& Chimimba, 2005). Crocidurinae are ironically characterized by relatively low metabolic rates compared with many other members of the Soricinae such as the European descended shrews (Vogel, 1976), and comparative studies may potentially shed some light on differences in their locomotor activity patterns.

Circadian systems and activity patterns have been extensively documented in rodents (Benstaali et al., 2001; Roll et al., 2006; Refinetti, 2007) while those of insectivores and in particular southern African soricids remain depauperate. Little is known about the activity of members of the genus Crocidura from southern Africa (Skinner \& Chimimba, 2005) and activity has only been anecdotally reported for a few species. In addition to the few quantitative studies conducted on the locomotor activity patterns of Crocidura, the associated free-running periods under constant lighting conditions remain unknown for any African shrew to date. Furthermore, the secretive nature and the difficulty of trapping shrews have precluded them from detailed studies. Reports on non-African shrews (Mann \& Stinson, 1957; Ingles, 1960; Richardson, 1973; Rust, 1978; Martin, 1983; Rychlik, 2005) intimate that crocidurid shrews may be active both during the day and at night, but there is little quantification of this and they are considered fundamentally nocturnal (Meester, 1963; Baxter, Goulden \& Meester, 1979; Dickman, 1995; Skinner \& Chimimba, 2005).
Crocidura cyanea presents an interesting model to increase our knowledge on the chronobiology of these poorly studied African insectivores. To date, it is unknown if these small mammals possess an endogenous rhythm of locomotory activity. We aimed to ascertain if the locomotory activity rhythm of C. cyanea is capable of entrainment to the light-dark cycle and furthermore to quantitatively describe how activity is distributed across the 24-h day. We further aimed to determine whether such a rhythm is endogenously controlled and to calculate the period of the free-running rhythm (Т) under constant dark conditions. We predicted that C. cyanea would exhibit a preference for the dark phase and that the free-running period will be $<24 \mathrm{~h}$ as is speculated for nocturnal mammals according to Aschoff $\mathrm{s}$ rule (Aschoff, 1981).

\section{Materials and methods}

\section{Animal capture and maintenance}

Nine male $(14.8 \pm 2.6 \mathrm{~g})$ and four female $(13.6 \pm 2.37 \mathrm{~g}) \mathrm{C}$. cyanea, were collected from a private plot outside of Tzaneen, Limpopo Province, South Africa $\left(23^{\circ} 49 \mathrm{~S}, 30^{\circ} 10 \mathrm{E}\right)$ between January and March in 2009 using Sherman live traps (H.B. Sherman Traps Inc., Tallahassee, FL, USA). The traps were baited with a mixture of peanut butter, oats, canned fish and/or canned dog food and were set before dusk and checked at dawn. Animals were housed individually in polyurethane cages $(60 \times 30 \times 30 \mathrm{~cm})$ in a room illuminated by fluorescent white lights $( \pm 500 \mathrm{~lx})$, at a constant ambient temperature of $25^{\circ} \pm 1^{\circ} \mathrm{C}$ and c. $60 \%$ relative humidity.

Each cage was lined with a layer of wood shavings, a small box was provided as shelter and an infra-red captor (Quest PIR internal passive infrared detector; Elite security products, Electronic lines, UK) was fitted centrally on a wooden bar above the cage. The infrared captors recorded activity collectively as per-minute readings to a computer outside the room, using the computer program VitalView (VitalView, Minimitter Co., Sunriver, OR, USA; http:// www.minimitter.com). The animals were provided with fresh water and canned cat food daily at random times and occasionally given grated carrot or apple.

The guidelines of the American Society of Mammalogists (http://www.mammalogy.org/committees/index.asp; Animal Care and Use Committee, 1994) were used to maintain live animals and all experimental techniques were approved by the Animal Ethics Committee of the University of Pretoria, Pretoria, South Africa (ethics clearance number ec015-08).

\section{Experimental protocol}

All animals were maintained on a 12L:12D light cycle and allowed to acclimatize to these lighting conditions for 7 days before the actual recording of the locomotor activity rhythms being recorded. When recording started, the lighting conditions remained the same throughout the first light cycle, 
the LD cycle (12 L: $12 \mathrm{D})$, which continued for c. 14 days. The LD cycle enabled us to determine whether $C$. cyanea could entrain their locomotor activity to a light-dark cycle and to investigate how activity is distributed across the 24-h day. Following the LD cycle, the shrews were immediately placed on a DD cycle (12D:12D) during which the animals were exposed to constant darkness (DD) for a period of 10 days. From the DD cycle, we were able to determine whether any circadian locomotor activity rhythms observed during the LD cycle were endogenously controlled and also to estimate the period of the free-running rhythm for $C$. cyanea. The final light cycle, the DL cycle, consisted of an inverse LD cycle (12D:12L) and continued for c. 14 days. If the animals displayed a reversed activity rhythm when they are subjected to the DL cycle and all other factors remain the same, it would provide further evidence for the photic-entrainment of their locomotor activity rhythms by means of the light-dark cycle.

The activity data were downloaded and converted to double-plotted actograms of consecutive days using ActiView (ActiView, Minimitter Co., Sunriver, OR, USA; http://www.minimitter.com) software. Further statistical analyses were performed using Microsoft Excel ${ }^{\mathrm{TM}}$ and SPSS 13.00 (SPSS Inc., Chicago, IL, USA).

\section{Data analysis}

Data were analysed in three ways. Firstly, basic activity patterns were interpreted by a visual examination of the actograms and involved determining the daily onset and offset times of activity each day. The onset of activity marked the beginning of the active period (a) and the offset of activity the end of the active period. The active periods consisted of a continuous stretch of short alternating active and inactive phases; animals most likely only rested rather than slept during these inactive phases, which lasted only a few minutes (Saarikko \& Hanski, 1990). Secondly, the period of the endogenous free-running rhythm $(t)$ was determined with the ActiView periodogram functionality. The percentage of activity occurring during light and dark phases, the active period (a) as well as the phase angle of entrainment (c) were computed. The percentage of activity verified whether animals were either nocturnal (more than $70 \%$ of activity allocated to the dark phase) or diurnal (more than $70 \%$ of activity allocated to the light phase) and was calculated for each animal as the sum of its activity during the light or dark phase, divided by the total daily activity and multiplied by 100 . Total percentage of activity was given as the mean percentage of activity for all animals. The time difference (in hours) between daily activity onset and offset times yielded a, and c was the time difference (in hours) between the onset of activity and the time of lights on or off. Activity onset and offset values were given as actual time values (e.g. 14h00) while c, $t$ and $a$ were given as values of time in duration. Standard deviations were indicated where applicable. In order to calculate the approximate proportion of the day during which the animals were active, the mean $a$ were divided by $24 \mathrm{~h}$ and multiplied with 100 .
Lastly, differences in $a$ for all animals between different light cycles were analysed with the Wilcoxon signed ranks tests selected for missing values $(\mathrm{P}<0.05)$.

\section{Results}

\section{LD cycle (12 L:12 D)}

All shrews entrained their locomotor activity to a particular phase during the LD cycle. C. cyanea primarily exhibited a pattern of locomotor activity confined to the dark phase of the light/dark cycle (Fig. 1) with a total percentage of activity of $78.9 \pm 15.8 \%$ during the dark phase and $21.0 \pm 15.8 \%$ during the light phase (Fig. 2). The animal with the highest nocturnal activity carried out $99.0 \%$ of its activity during the dark phase (Fig. 3). Two animals displayed $<70 \%$ of their activity to the dark phase of the LD cycle (animal \# 1: 57.7\%; animal \# 5: $43.9 \%$; Fig. 3). Most of the animals displayed some activity during the light phase, particularly during the second half of the light phase. This regular occurrence of 'afternoon' activity was characterized by a mean onset of activity at $15 \mathrm{~h} 52$ and a mean $\mathrm{c}$ of $3.15 \pm 2.26 \mathrm{~h}$ despite lights going off at $18 \mathrm{~h} 00$. Activity onset varied greatly between individuals, from the earliest at $12 \mathrm{~h} 35$ to the latest at $19 \mathrm{~h} 09$ and the mean offset of activity was at $06 \mathrm{~h} 33$, with lights on at $06 \mathrm{~h} 00$.

It was clearly observed from all of the actograms that the animals were rarely continually active for more than $1 \mathrm{~h}$, but rather displayed polyphasic activity; continual bouts of activity separated by short resting phases throughout their active periods. There was great variation in $a$ between individuals, ranging from $06.33 \pm 02.62$ to $15.39 \pm 02.91 \mathrm{~h}$ with a mean total of $10.83 \pm 02.70 \mathrm{~h}$ making the animals active approximately $45.1 \%$ of the day. Only one animal (\# 3) displayed a bimodal activity pattern, which was strictly confined to the dark phase (Fig. 4).

\section{DD cycle (12 D:12 D)}

C. cyanea displayed distinct free-running rhythms under constant dark conditions, which provided evidence for the endogenous control of the circadian rhythm. The free-running rhythms were always close to, but less than $24 \mathrm{~h} ; 10$ individuals had robust free-running rhythms with $t$ ranging from 22.4 to $24.0 \mathrm{~h}$. A mean $t$ of $23.00 \pm 0.55 \mathrm{~h}$ was obtained and excluded three animals, which had unclear free-running rhythms. Actograms representative of animals with robust free-running rhythms and uneven free-running rhythms are shown in Fig. 5.

Most animals showed signs of bimodal activity after a few days during the DD cycle. Bimodality did not occur consistently over consecutive days and the DD cycle was too short for a detailed investigation of the split activity components. At $13.17 \pm 01.78 \mathrm{~h}$, the mean $a$ was significantly higher during the DD cycle than during the LD cycle (Wilcoxon test: $\mathrm{Z}=-2.040 ; n=12 ; P=0.04$ ) but had a smaller range between the minimum $(11.14 \pm 03.76 \mathrm{~h})$ and maximum (17.35 $\pm 06.22 \mathrm{~h}$ ) between individuals. The animals were thus active 


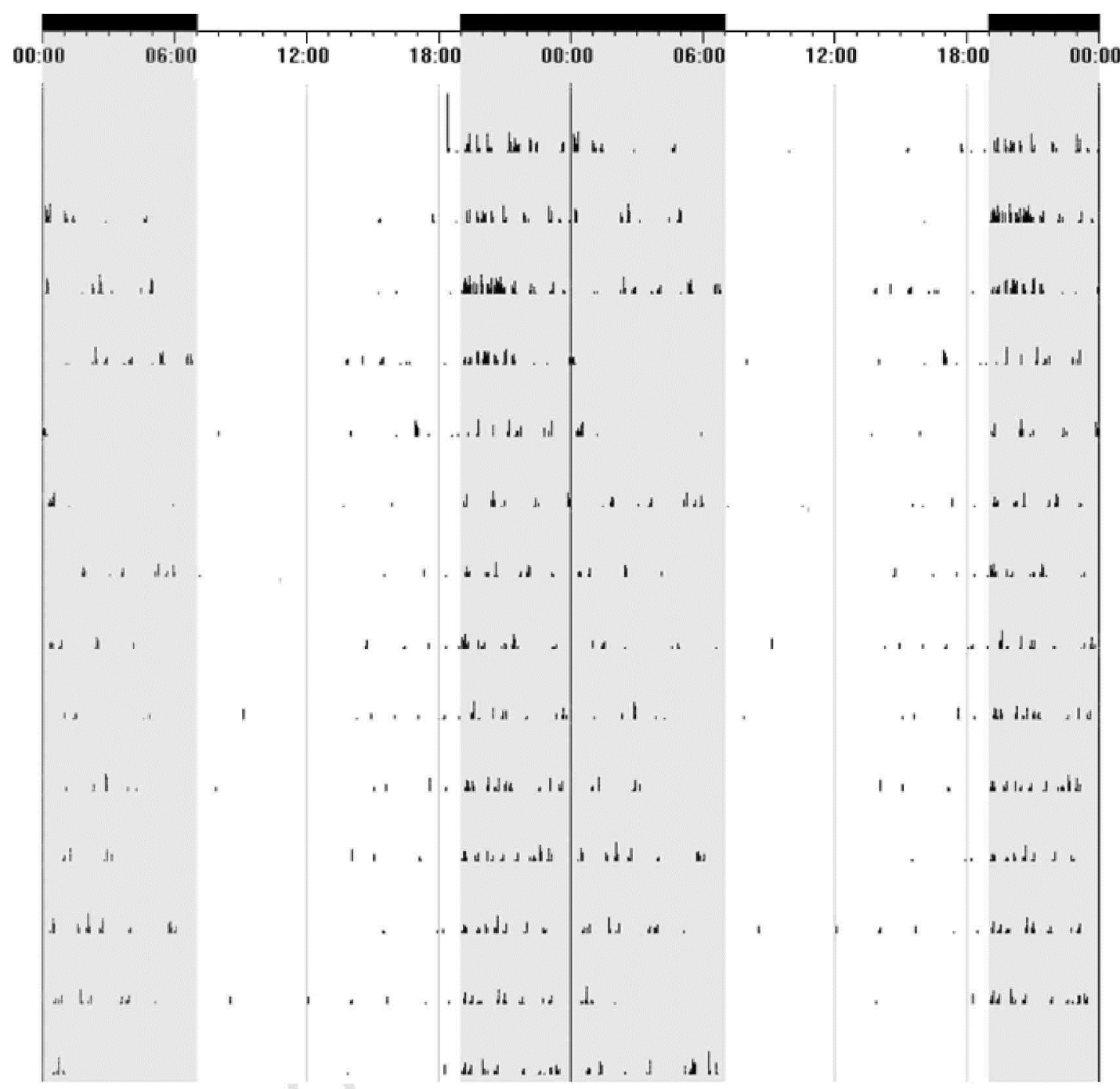

Figure $1 \mathrm{~A}$ double-plotted actogram displaying the typical entrainment of locomotor activity of the reddish-grey musk shrew Crocidura cyanea, to the light-dark cycle during the LD cycle. The dark phase is represented by the shaded areas, whereas the light phase is represented by unshaded areas. The $\mathrm{x}$-axis represent the 24-h day, and the y-axis consecutive days. Activity is shown as the accumulative data points per minute.

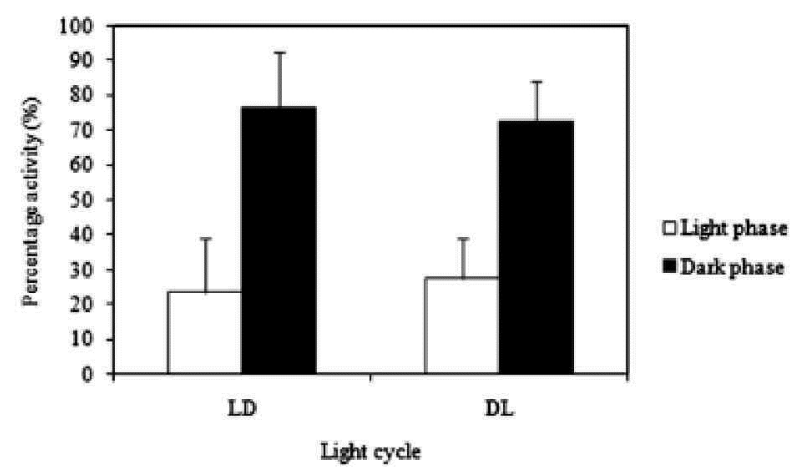

Figure 2 The total percentage of activity of the reddish-grey musk shrew Crocidura cyanea during the light and dark phases obtained during the LD cycle and the DL cycle. for a larger proportion of the day (54\%) than during the LD cycle. Throughout the DD cycle, animal \# 3 maintained bimodal activity similar to that shown during the LD cycle and interestingly, animal \#11 dramatically increased its locomotor activity by $69.01 \%$ during the DD cycle compared with during the preceding LD cycle.

\section{DL cycle (12:12)}

When the animals were subjected to an inverse LD cycle, they readjusted their locomotor activity rhythms to the new light regime within 2 days. The total percentage of light- and dark-phase activity was relatively similar to that obtained during the LD cycle. The total percentage of activity remained highest during the dark phase $(715 \pm 11.5 \%)$ and lowest during the light phase (28.5 $\pm 11.5 \%$; Fig. 2). Animal \#5, 

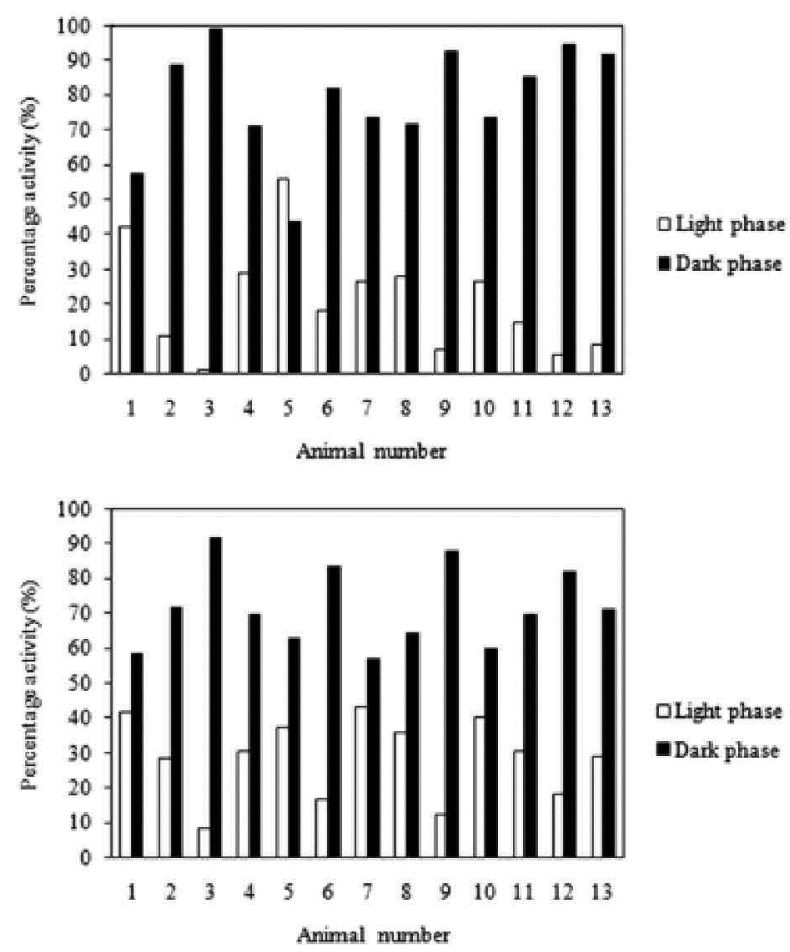

Figure 3 The mean percentage of activity for all 13 individuals of the reddish-grey musk shrew Crocidura cyanea during the (a) LD cycle and the (b) DL cycle.

which displayed more activity during the light phase during the LD cycle, now displayed more activity during the dark phase of the DL cycle by increasing its dark-phase activity by $18.84 \%$. Nocturnal activity of six animals exceeded $70 \%$ and animal \# 3 still had the highest percentage of dark phase activity (91.6\%; Fig. 3). Although the percentage of activity allocated to the light and dark phases were similar between the LD cycle and DL cycle, locomotor activity nevertheless differed between these two light cycles. In contrast to the activity patterns displayed during the LD cycle, there was a split in the active phases, divided by a mean rest phase of 8.99 $\mathrm{h}$, observed for nine of the animals under the DL cycle. This bimodal organization of activity was most likely consequent to some effect caused by the preceding DD cycle during which animals displayed some splitting of their activity. In order to calculate a, the two split active phases were summed and yielded a mean total a of $09.31 \pm 01.62 \mathrm{~h}$, which was not significantly different from the mean total a during the LD cycle (Wilcoxon test: $\mathrm{Z}=1.274 ; n=10 ; P=0.20$ ). Activity thus occurred c. $38.8 \%$ of the day. It was difficult to determine $\mathrm{c}$ for five of the animals but a mean $\mathrm{c}$ of $01.17 \pm 2.04 \mathrm{~h}$ was obtained for the remaining eight animals.

\section{Discussion}

The environmental light-dark cycle is fundamental to the entrainment of circadian rhythms of most mammals (Kumar, 1997; Goldman, 1999; Benstaali et al., 2001). C. cyanea is no exception as its locomotor activity is clearly entrained to the continuous exposure of $12 \mathrm{~h}$ of light followed by $12 \mathrm{~h}$ of dark (LD cycle). The species also displayed a strong preference for locomotor activity during the dark cycle but activity was not restricted to the dark phase. Even following a cycle of constant darkness, the locomotor activity pattern quickly responded and readjusted to an inverse LD cycle during which $C$. cyanea again displayed a preference for the dark phase. Existing data on the activity patterns of African shrews are limited and the present study is one of very few studies to investigate the circadian locomotor activity rhythm of $C$. cyanea and also present a free-running period for a South African shrew.

Locomotor activity was recorded for many species in the genera Sorex and Blarina: (Doucet \& Bider, 1974; Rust, 1978; Ohdachi, 1994; Brandt \& McCay, 2005), including some southern African species: Crocidura flavescens, Crocidura pilosa; Crocidura hirta and C. cyanea, Crocidura mariquensis (Meester, 1963; Baxter et al., 1979; Dickman, 1995). In the present study, $85 \%$ of $C$. cyanea were nocturnal during the LD cycle and the mean proportion of activity allocated to the dark phases of the LD and DL light cycles exceeded $70 \%$. The dark-phase activity of $C$. cyanea was almost four times that of the light-phase activity. This proportion of night and day activity is similar to that of a similar-sized southern African crocidurid, C. mariquensis (Baxter et al., 1979), and agrees with the findings of Dick-man (1995) who trapped c. $64 \%$ of C cyanea, and $60 \%$ of C. hirta during the night. Interestingly, although Skinner \& Chimimba (2005) report that $C$. cyanea as being trapped both during the day and at night, and also being found in barn owl Tyto alba pellets, they suggested that the species may be sporadically active throughout the 24-h period.

The time of feeding had little effect on the onset of activity and because the animals were fed at random times each day, they were unable to entrain their activity to the feeding times. C cyanea were also provided with a sufficient amount of food primarily during the day (light phase) yet still preferred being more active at night and displayed activity dispersed throughout primarily the dark phase. Therefore, apart from the fact that other non-foraging activities play a role in an animal's mobility, the activity pattern observed in this study reflected an energetic lifestyle bound by physiological constraints. Shrews have high energetic requirements (Lindstedt, 1980; Saarikko \& Hanski, 1990) and are often referred to as voracious feeders, rightly so, considering that they are capable of killing prey much larger than their own body size and may consume amounts of food exceeding their own body mass each day (Hamilton Jr, 1930; Hamilton Jr, 1944; Meester, 1963; Rychlik, 1999). Therefore, in addition to the challenges related to obtaining food or killing prey, the rate that shrews consume food appears to also be limited by their digestive tracts (Saarikko \& Hanski, 1990). This is overcome through polyphasic activity such as was observed in C. cyanea a compilation of as many as 15 short active phases per day each lasting around 0.1-3 h (Whittaker \& Feldhamer, 2005). These results therefore suggest that $C$ cyanea perhaps makes use 


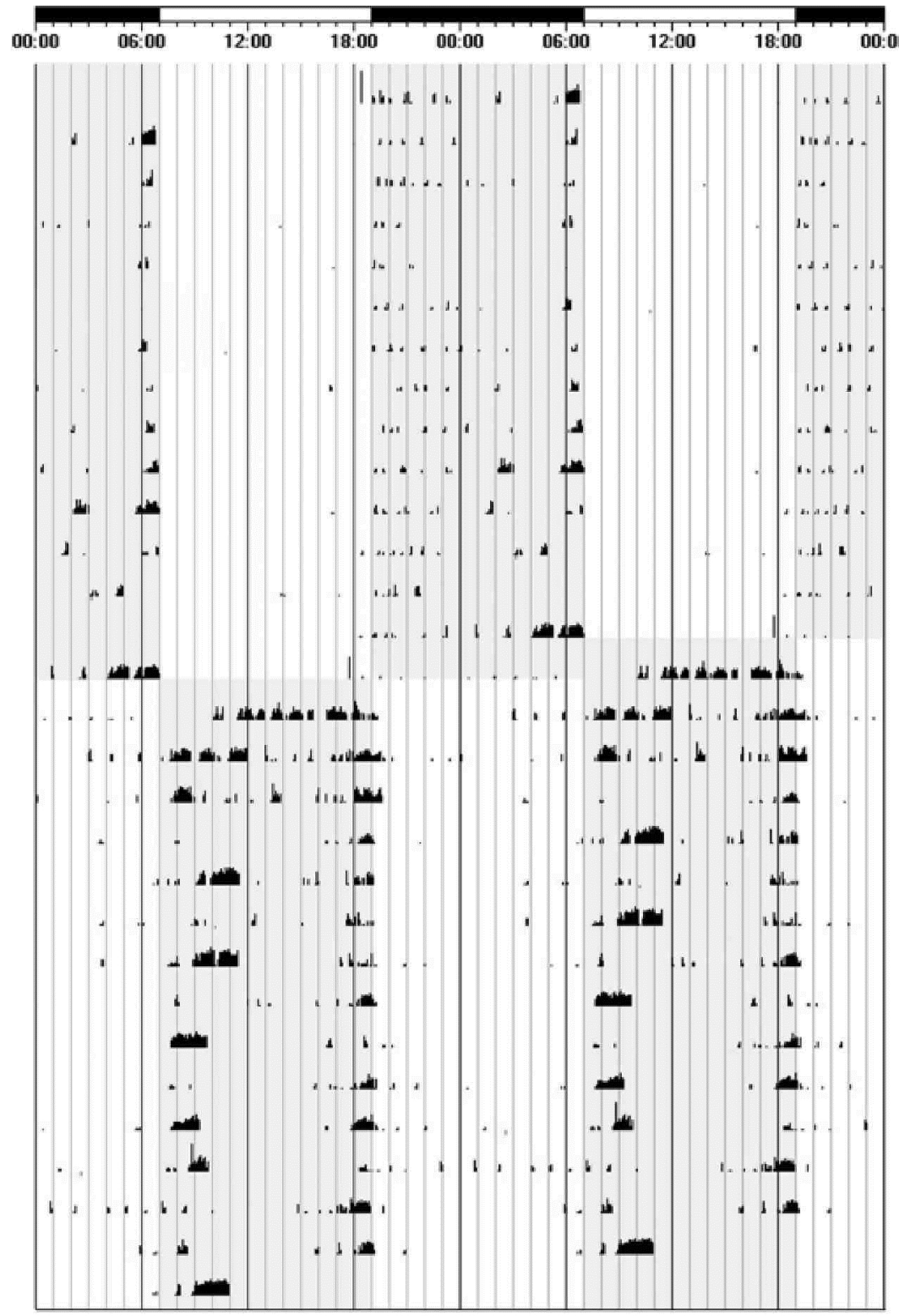

Figure 4 Bimodal locomotor activity observed for the reddish-grey musk shrew Crocidura cyanea (animal \#3) during the LD cycle (top) and DL cycle (bottom).

of some diurnal activity to meet daily energetic requirements, most likely when food resources are scarce.

The entrainment of locomotor activity to a specific phase of the day may be as a result of physiological or morphological constraints and commonly reflects the time most advantageous to the animal, that is, when food resources are most abundant and attainable or when predators are least active (Saarikko \& Hanski, 1990; Brandt \& McCay, 2005). C. cyanea possesses a few morphological features commonly characteristic of nocturnal animals; they possess large ears and a very sensitive and elongated nose but uncharacteristically have microphthalmic eyes and thus rather than using vision may make use of smell and hearing to detect food in the dark in the leaf litter (Kronfeld-Schor \& Dayan, 2008). As its name also suggests, the reddish-grey musk shrew is able to use its musky odour for various communicative purposes and is also capable of making high-pitched sounds (Eadie, 1938; Crowcroft, 1955). Many nocturnal animals are known to communicate via aromas and vocal sounds (Kronfeld-Schor \& Dayan, 2008). Furthermore, all soricids are insectivores (Hamilton Jr, 1930) and therefore nocturnal activity in this species is most likely synchronized with the active phases of most insects, which is usually at night. In C. cyanea, a strong nocturnal activity rhythm may also allow them to avoid high ambient temperatures during the day. Shrews possess high surface-to-volume ratios and consequently they easily gain or lose heat (Lindstedt, 1980; Martin, 1983). This is further supported by the fact that the daytime activity primarily occurred during the afternoons, which under natural conditions would be characterized by lower ambient temperatures. 

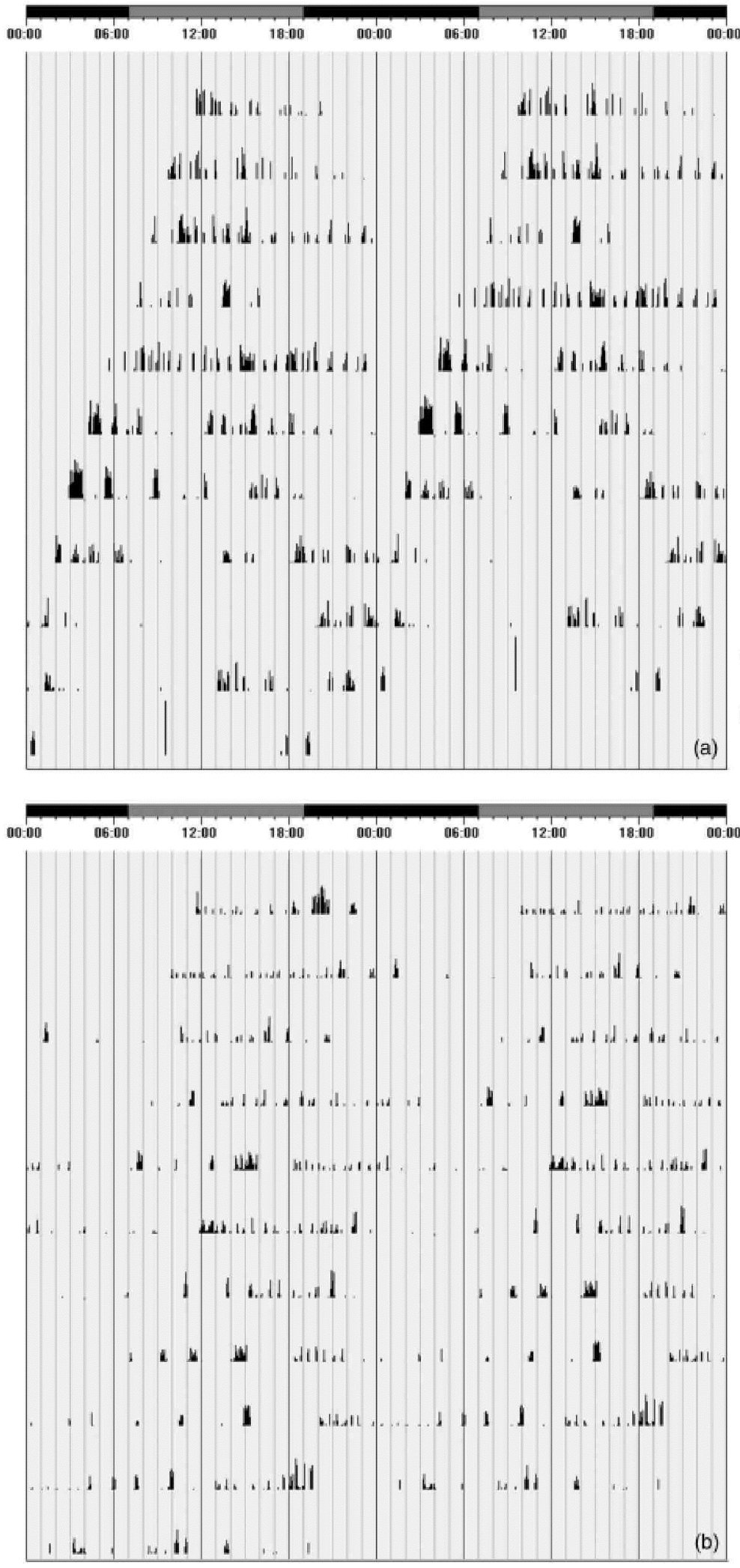

(a)
Figure 5 Actograms representative of individuals of the reddish-grey musk shrew Crocidura cyanea Africa examined under constant dark (DD cycle), which displayed (a) robust free-running rhythms (animal \# 5) and (b) 'sloppy' free-running rhythms (animal \# 2). 
The endogenous rhythm of locomotor activity was revealed once the activity rhythms of all animals free-ran in the absence of a time giver (DD cycle). The starting point of the free-run also coincided with the phase angle of entrainment during the LD cycle, which suggests that the light-dark cycle was most likely the principle entraining agent rather than the rhythm being the consequence of masking (Aschoff, 1981). Although our results concurred with the notion for $i$ to be more than $24 \mathrm{~h}$ in diurnal species and $<24 \mathrm{~h}$ in nocturnal species, the Aschoff rule (Aschoff, 1981), it is difficult to speculate on the reasons for the $i$ obtained. This may arise simply because the free-running period is the result of the co-action of factors internal and external to the animal (Pittendrigh \& Daan, 1974; Aschoff, 1981), which for C. cyanea need further investigation.

In conclusion, under experimental conditions $C$. cyanea was found to be primarily nocturnal yet able to exhibit a small amount of intermittent activity during the day. All individuals displayed polyphasic activity and the overall activity pattern is thus consistent with that of small mammals with high energetic lifestyles, such as the soricid shrews from America and Europe. This species also appears to be morphologically adapted to the night. The environmental light-dark cycle plays a foundational role in entraining the internal locomotor activity rhythm in $C$. cyanea $(z<24 \mathrm{~h})$ to that phase of the day most favourable to them. Nocturnality is further supported by the free-running endogenous rhythm being $<24 \mathrm{~h}$, which concurs with Aschoff s rule.

\section{Acknowledgements}

The research was supported by a Department of Science and Technology/National Research Foundation South African Research Chair of Mammal Behavioural Ecology and Physiology awarded to NCB. IVDM acknowledges a scholarship from the South African National Research Foundation (NRF). The work was supported by a collecting permit from the Department of Nature Conservation in Limpopo Province.

\section{References}

Animal Care and Use Committee. (1994). Guidelines for the capture, handling and care of mammals as approved by the American Society of Mammalogists. J. Mammal. 79, 1416-1431.

Aschoff, J. (1960). Exogenous and endogenous components in circadian rhythms. Cold Spring Harb. Symp. Quant. Biol. $25,11-28$.

Aschoff, J. (1981). Freerunning and entrained circadian rhythms. In Handbook of behavioral neurobiology: Biological rhythms: 81-93. Aschoff, J. (Ed.) New York: Plenum Press.
Baxter, R.M., Goulden, E.A. \& Meester, J. (1979). The activity patterns of some southern African Crocidura in captivity. Act $a$ Theriol. 24, 61-68.

Benstaali, C, Mailloux, A., Bogdan, A., Auzeby, A. \& Touitou, Y. (2001). Circadian rhythms of body temperature and motor activity in rodents. Their relationships with the light-dark cycle. Life Sci. 68, 2645-2656.

Brandt, AJ. \& McCay, T.S. (2005). Temperature and photo-period effects on activity of the northern short-tailed shrew (Blarina brevicauda). Bios 76, 9-14.

Crowcroft, P. (1955). Notes on the behavior of shrews. Behaviour 8, 63-80.

Daan, S. \& Aschoff, J. (1981). The entrainment of circadian systems. In Handbook of behavioral neurobiology: Circadian clocks: 1-28. Takahashi, J.S., Turek, F.W. \& Moore, R.Y. (Eds). New York: Plenum Press.

Dickman, C.R. (1995). Diets and habitat preferences of three species of crocidurine shrews in arid southern Africa. J. Zool. (Lond.) 237, 499-514.

Doucet, G.J. \& Bider, J.R. (1974). The effects of weather on the activity of the masked shrew. J. Mammal. 55, 348-363.

Eadie, W.R. (1938). The dermal glands of shrews. J. Mammal. 19, 171-174.

Getz, L.L. (1961). Responses of small mammals to live-traps and weather conditions. Am. Midl. Nat. 66, 160-170.

Goldman, B.D. (1999). The circadian timing system and reproduction in mammals. Steroids 64, 679-685.

Hamilton, W.J. Jr (1930). The food of the soricidae. J. Mammal. 11, 26-39.

Hamilton, W.J. Jr (1944). The biology of the little short-tailed shrew, Cryptotis parva. J. Mammal. 25, 1-7.

Haus, E., Lakatua, D.J., Sackett-Lundeen, L., Dumitriu, L., Nicolau, G., Petrescu, E., Plinga, L. \& Bogdan, C. (1998). Interaction of circadian, ultradian and infradian rhythms. In Biological clocks: Mechanisms and applications: 141-150. Touitou, Y. (Ed.). Amsterdam: Elsevier Science B.V.

Ingles, L.G. (1960). A quantitative study on the activity of the dusky shrew (Sorex vagrans obscurus). Ecology 41, 656-660.

Kelt, DA., Meserve, P.L., Nabors, L.K., Forister, M.L. \& Gutierrez, J.R. (2004). Foraging ecology of small mammals in semiarid Chile: the interplay of biotic and abiotic effects. Ecology 85, 383-397.

Kronfeld-Schor, N. \& Dayan, T. (2008). Activity patterns of rodents: the physiological ecology of biological rhythms. Biol. Rhythm Res. 39, 193-211.

Kumar, V. (1997). Photoperiodism in higher vertebrates: an adaptive strategy in temporal environment. Indian J. Exp. Biol. 35, 427-437.

Lindstedt, S.L. (1980). Energetics and water economy of the smallest desert mammal. Physiol. Zool. 53, 82-97.

Mann, P.M. \& Stinson, R.H. (1957). Activity of the short-tailed shrew. Can. J. Zool. 35, 171-177.

Martin, I.G. (1983). Daily activity of short-tailed shrews (Blarina brevicauda) in simulated natural conditions. Am. Midl. Nat.109, 136-144. 
Meester, J. (1963) A systematic revision of the shrew genus Crocidura in southern Africa. Transvaal Museum Memoir No. 13.

Mosko, S. \& Moore, R.Y. (1978). Neonatal suprachiasmatic nucleus ablation: absence of functional and morphological plasticity. Proc. Natl. Acad. Sci. USA 75, 6243-6246.

Nagy, K.A., Girard, I.A. \& Brown, T.K. (1999). Energetics of free-ranging mammals, reptiles, and birds. Annu. Rev. Nut. $19,247-277$.

Ohdachi, S. (1994). Total activity rhythms of three soricine species in Hokkaido. /. Mammal. Soc. Jpn. 19, 89-99.

Pittendrigh, C.S. \& Daan, S. (1974). Circadian oscillations in rodents: a systematic increase of their frequency with age. Science 186, 548-550.

Refinetti, R. (2007). Enhanced circadian photoresponsiveness after prolonged dark adaptation in seven species of diurnal and nocturnal rodents. Physiol. Behav. 90, 431-437.

Richardson, J.H. (1973). Locomotory and feeding activity of the shrews, Blarina brevicauda and Suncus murinus. Am. Midi. Nat. 90, 224-227.

Roll, U., Dayan, T. \& Kronfeld-Schor, N (2006). On the role of phylogeny in determining activity patterns of rodents. Evol. Ecol. 20, 479-490.

Rust, A.K. (1978). Activity rhythms in the shrews, Sorex sinuosus Grinnell and Sorex trowbridgii Baird. Am. Midi. Nat. 99, 369-382.

Rychlik, L. (1999). Changes in prey size preferences during > successive stages of foraging in the Mediterranean water shrew Neomys anomalus. Behaviour 136, 345-365.

Rychlik, L. (2005). Overlap of temporal niches among four sympatric species of shrews. Acta Theriol. 50, 175-188.

Saarikko, J. \& Hanski, I. (1990). Timing of rest and sleep in foraging shrews. Anim. Behav. 40, 861-869.
Sidorovich, V.E., Polozov, A.G. \& Solovej, I.A. (2008). Niche separation between the weasel Mustela nivalis and the stoat M. erminea in Belarus. Wildl. Biol. 14, 199-210.

Skinner, J.D. \& Chimimba, C.T. (2005). The mammals of the southern African subregion. Cambridge: Cambridge University Press.

Shkolnik, A. (1971). Diurnal activity in a small desert rodent. Int. J. Biometeorol. 15, 115-120.

Stephan, F.K. \& Zucker, I. (1972). Circadian rhythms in drinking behavior and locomotor activity of rats are eliminated by hypothalamic lesions. Proc. Natl. Acad. Sci. USA 69 , 1583-1586.

Travis, S.E. \& Armitage, K.B. (1972). Some quantitative aspects of the behavior of marmots. Trans. Kansas. Acad. Sci. 75, 308-321.

Vieira, E.M. \& Baumgarten, L.C. (1995). Daily activity patterns of small mammals in a cerrado area from central Brazil. /. Trop. Ecol. 11, 255-262.

Villafuerte, R., Kufner, M.B., Delibes, M. \& Moreno, S. (1993). Environmental factors influencing the seasonal daily activity of the European rabbit (Oryctolatus cuniculus) in a Mediterranean area. Mammalia 57, 341-347.

Vogel, P. (1976). Energy consumption of European and African shrews. Acta Theriol. 21, 195-206.

Whittaker, J.C. \& Feldhamer, G.A. (2005). Population dynamics and activity of southern short-tailed shrews (Blarina carolinensis) in southern Illinois. /. Mammal. 86, 294-301.

Wojcik, J.M. \& Wolsan, M. (1998). Evolution of shrews. Mammal Research Institute, Polish Academy of Sciences, Bialowieza. 